\title{
Physical and chemical changes of rapeseed meal proteins during toasting and their effects on in vitro digestibility
}

Sergio Salazar-Villanea ${ }^{1,2^{*}}$ (D), Erik M. A. M. Bruininx ${ }^{2,3}$, Harry Gruppen ${ }^{4}$, Wouter H. Hendriks ${ }^{2}$, Patrick Carré ${ }^{5}$, Alain Quinsac ${ }^{6}$ and Antonius F. B. van der Poel ${ }^{2}$

\begin{abstract}
Background: Toasting during the production of rapeseed meal (RSM) decreases ileal crude protein (CP) and amino acid (AA) digestibility. The mechanisms that determine the decrease in digestibility have not been fully elucidated. A high protein quality, low-denatured, RSM was produced and toasted up to 120 min, with samples taken every $20 \mathrm{~min}$. The aim of this study was to characterize secondary structure and chemical changes of proteins and glucosinolates occurring during toasting of RSM and the effects on its in vitro CP digestibility.

Results: The decrease in protein solubility and the increase of intermolecular $\beta$-sheets with increasing toasting time were indications of protein aggregation. The contents of NDF and ADIN increased with increasing toasting time. Contents of arginine, lysine and O-methylisourea reactive lysine (OMIU-RL) linearly decreased with increasing toasting time, with a larger decrease of OMIU-RL than lysine. First-order reactions calculated from the measured parameters show that glucosinolates were degraded faster than lysine, OMIU-RL and arginine and that physical changes to proteins seem to occur before chemical changes during toasting. Despite the drastic physical and chemical changes noticed on the proteins, the coefficient of in vitro CP digestibility ranged from 0.776 to 0.750 and there were no effects on the extent of protein hydrolysis after $120 \mathrm{~min}$. In contrast, the rate of protein hydrolysis linearly decreased with increasing toasting time, which was largely correlated to the decrease in protein solubility, lysine and OMIU-RL observed. Rate of protein hydrolysis was more than 2-fold higher for the untoasted RSM compared to the 120 min toasted material.
\end{abstract}

Conclusions: Increasing the toasting time for the production of RSM causes physical and chemical changes to the proteins that decrease the rate of protein hydrolysis. The observed decrease in the rate of protein hydrolysis could impact protein digestion and utilization.

Keywords: Hydrolysis rate, In vitro protein digestibility, Rapeseed meal, Reactive lysine, Secondary structure

\section{Background}

Rapeseed meal (RSM) is the most important protein source utilized in commercial swine and poultry diets after soybean meal [1-3]. The production process of RSM involves toasting to remove the organic solvent remaining after solvent extraction of the oil and to

\footnotetext{
* Correspondence: sergio.salazarvillanea@ucr.ac.cr

'Wageningen Livestock Research, P.O. Box 338, 6700 AH Wageningen, The Netherlands

${ }^{2}$ Animal Nutrition Group, Wageningen University \& Research, P.O. Box 338, 6700 AH Wageningen, The Netherlands

Full list of author information is available at the end of the article
}

inactivate antinutritional factors present such as glucosinolates [4]. Direct application of live steam is used during toasting to complete the solvent removal, which also increases the moisture content. The toasting process time usually ranges from 60 to $90 \mathrm{~min}$ at $100-110{ }^{\circ} \mathrm{C}$, which can increase the variation in the lysine content and ileal digestibility of most AA in RSM $[4,5]$. The coefficient of variation of the apparent ileal digestibility of lysine in poultry increased from $1.4 \%$ in the solvent extracted meal to $5.4 \%$ after toasting [5]. 
Both physical and chemical changes of proteins due to thermal processing can influence protein digestibility [6]. Autoclaving at $120{ }^{\circ} \mathrm{C}$ for $20 \mathrm{~min}$ increased the proportion of random coil in the secondary protein structure of legume seeds, which is related to protein denaturation and increased CP in vitro digestibility [7]. At the same time, appearance of intermolecular $\beta$-sheets, linked to decreased protein digestibility, was reported in the same study. The net effect on the in vitro crude protein $(\mathrm{CP})$ digestibility seems to be related to the ratio between both types of physical changes. Chemical changes can be the result of Maillard reactions or covalent crosslinking between amino acids (AA). Increasing the toasting time decreased the lysine and reactive lysine contents [8]. In addition, the standardized ileal digestibility of $\mathrm{CP}$ was reduced from 66 to $60 \%$ and that of lysine from 64 to $54 \%$ when the toasting time was increased from 48 to 93 min [8]. Chemical changes due to Maillard reactions were suggested to be responsible for the decrease in protein and amino acid digestibility. However, chemical changes of proteins due to Maillard reactions do not completely explain the reduction in the digestibility of all AA, as observed in that study. This suggests that also changes in the structure of proteins (e.g. secondary and tertiary) affect the digestion process.

The aim of the present experiment was to characterize the physical and chemical changes that occur to rapeseed proteins during toasting and the influence of these changes on in vitro $\mathrm{CP}$ digestibility. We hypothesize that increasing toasting times causes physical and chemical changes to rapeseed proteins, resulting in decreased in vitro $\mathrm{CP}$ digestibility.

\section{Methods}

Materials

A batch of commercially available winter 00-rapeseed (Brassica napus), harvested in the southwest of France in 2013, was used. All chemicals used were of analytical grade. Pepsin (2,000 FIP U/g) was obtained from Merck (Darmstadt, Germany), whilst pancreatin (grade IV from porcine pancreas), trypsin (type IX-S, 13,000-20,000 BAEE units/mg protein), chymotrypsin (type II, $>40$ units/mg protein), and peptidase from porcine intestinal mucosa (50-100 units/g solid) were obtained from Sigma-Aldrich (St Louis, MO, USA).

\section{Rapeseed meals preparation}

All processing of the rapeseed was conducted at the pilot plant of CREOL (Pessac, France). The batch of rapeseed was dried in a warm-air dryer at $70{ }^{\circ} \mathrm{C}$ to a moisture level of $5 \%(\mathrm{w} / \mathrm{w})$ (Fig. 1). After drying, the rapeseed was cold pressed (La Mecanique Moderne MBU 75 type, Arras, France) at $250 \mathrm{~kg} / \mathrm{h}$. Temperatures during pressing did not exceed $80{ }^{\circ} \mathrm{C}$. Continuous extraction of the cake by hexane was performed on a belt extractor (B-1930, Desmet-Ballestra, Zaventem, Belgium) at $160 \mathrm{~kg} / \mathrm{h}$ flow of the cake and $230 \mathrm{~L} / \mathrm{h}$ flow of solvent. Temperature of the rapeseed cake during solvent extraction did not exceed $55{ }^{\circ} \mathrm{C}$. The solvent remaining after solvent extraction of the oil was removed using indirect heat (i.e. without use of direct live steam) in a desolventizer-toaster (Schumacher type, Desmet-Ballestra, Zaventem, Belgium; 6 trays with a rotating arm and $1 \mathrm{~m}$ internal diameter) for $60 \mathrm{~min}$. Temperatures during desolventization were $90 \pm 3{ }^{\circ} \mathrm{C}$.

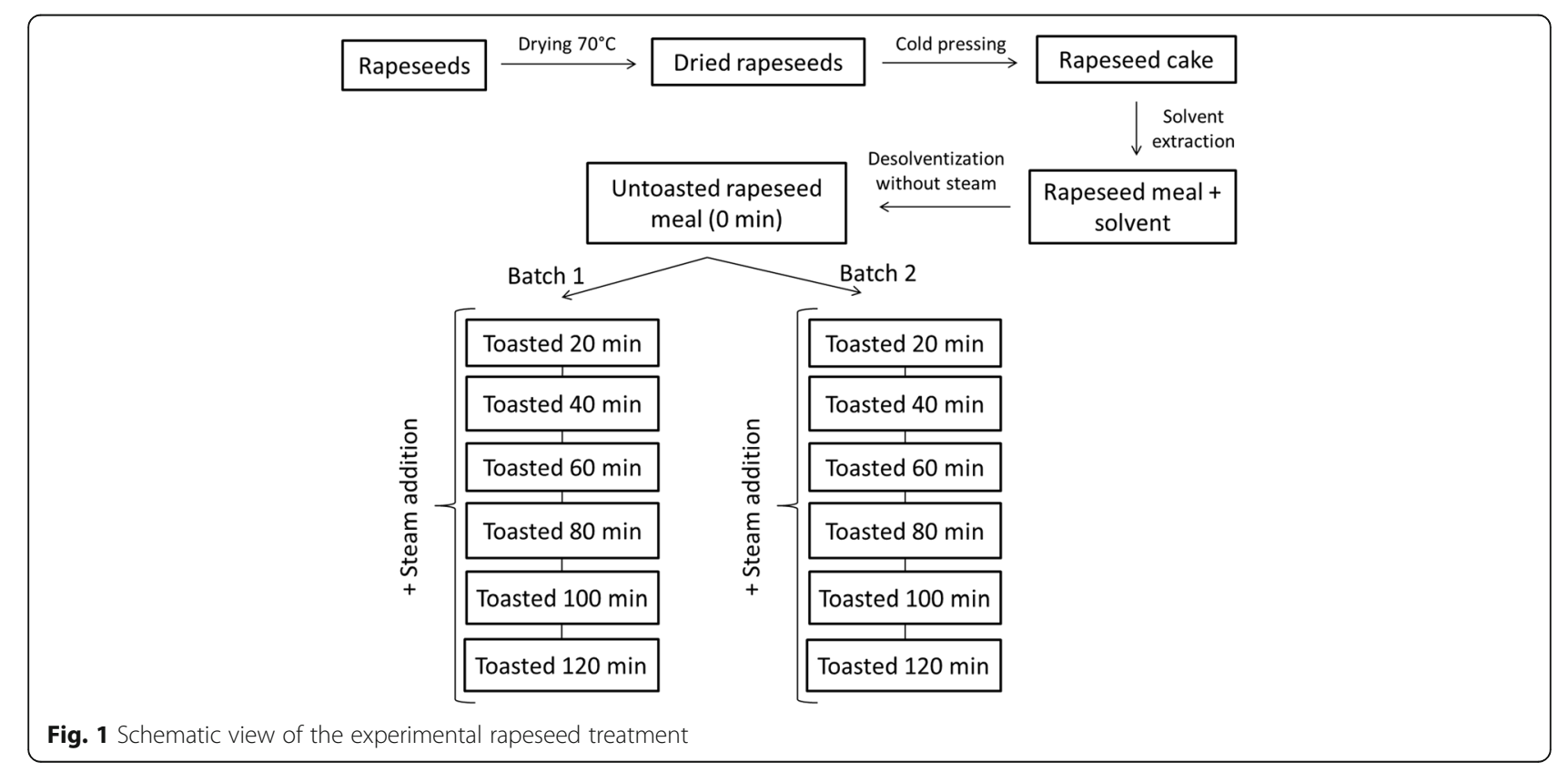


Spot samples $(5 \mathrm{~kg})$ were obtained after drying, coldpressing, hexane extraction, and desolventization with indirect heat.

A batch of $150 \mathrm{~kg}$ of the desolventized-untoasted RSM was toasted in the lower tray of the desolventizer-toaster with injection of live steam $(30 \mathrm{~kg} / \mathrm{h})$, whilst indirect steam pressure was set at 3 bars and arm rotations at $20 \mathrm{rpm}$. These conditions were maintained for $120 \mathrm{~min}$, with spot samples $(5 \mathrm{~kg})$ taken every 20 min through a door in the desolventizer-toaster. Monitoring of time was initiated when the temperature inside the desolventizer-toaster reached $100{ }^{\circ} \mathrm{C}$. A second batch of $150 \mathrm{~kg}$ of the desolventized-untoasted RSM was used for duplication of the toasting experiment on the next day (Fig. 1). The samples obtained from both toasted batches (in total 12 toasted RSM plus the untoasted RSM) were analyzed separately. Temperatures during toasting ranged from 107 to $112{ }^{\circ} \mathrm{C}$ on the first day and from 109 to $112{ }^{\circ} \mathrm{C}$ on the second day.

\section{Analytical methods}

The desolventized RSM and the toasted RSMs were ground to pass a $1 \mathrm{~mm}$ sieve using a centrifugal mill (ZM200, Retsch, Haan, Germany) at 8,000 rpm prior to chemical analysis. Samples (5 g) were re-ground using a ball (Ø $12 \mathrm{~mm})$ mill (MM2000, Retsch) at a frequency of 80 during $3 \mathrm{~min}$ and used for secondary structure, degree of denaturation, amino acid and reactive lysine analysis. All chemical and secondary structure analyses were performed in duplicate, except for reactive lysine, which was performed in triplicate.

\section{Nutrient contents}

Dry matter (DM) content was determined by ovendrying at $103{ }^{\circ} \mathrm{C}$ to constant weight according to ISO 6496 [9]. Nitrogen content was analyzed by combustion according to AOAC 968.06 (Thermo Quest NA 2100 Nitrogen and Protein Analyzer; Breda, the Netherlands) [10]. Nitrogen content in the nitrogen solubility index (NSI) and nitrogen linked to the acid detergent fiber (ADIN) determinations were measured using the Kjeldahl method according to ISO 5983 [11]. A conversion factor of 6.25 was used for the calculation of $\mathrm{CP}$ content from nitrogen. Crude fat content was determined according to ISO 734-2 [12]. The neutral detergent fiber (NDF) and acid detergent fiber (ADF) contents were determined using a fiber analyzer equipment (Fiber Analyzer, Ankom Technology, Macedon, $\mathrm{NY}$ ) according to a modification of the procedure of Van Soest et al. [13]. The NDF determination involved enzymatic incubation with $\alpha$-amylase and alcalase, but without addition of sodium sulfite. The ADIN content was determined in the residues after hydrolysis with acid detergent reagents.
For the determination of amino acid content, samples were hydrolyzed with $6 \mathrm{~mol} / \mathrm{L} \mathrm{HCl}$ at $110{ }^{\circ} \mathrm{C}$ for $23 \mathrm{~h}$ and the hydrolysates were adjusted to $\mathrm{pH} 2.2$ using $\mathrm{NaOH}$. Amino acids were determined by post column reaction with ninhydrin, after separation by ion exchange chromatography. Photometric detection was performed at $570 \mathrm{~nm}$ and at $440 \mathrm{~nm}$ for proline according to ISO 13903 [14]. Norleucine was used as an internal standard.

Reactive lysine was determined using a method described by Moughan and Rutherfurd [15]. In short, reactive lysine was converted into homoarginine by incubation with $\mathrm{O}$-methylisourea (OMIU) for $7 \mathrm{~d}$. Samples were subsequently hydrolyzed with $6 \mathrm{~mol} / \mathrm{L} \mathrm{HCl}$ at $110{ }^{\circ} \mathrm{C}$ for $23 \mathrm{~h}$ and the hydrolysates were adjusted using $\mathrm{NaOH}$ to $\mathrm{pH}$ 2.2. After separation by ion exchange chromatography, the homoarginine content was determined by post column reaction with ninhydrin using photometric detection at $570 \mathrm{~nm}$. The amount of OMIU-reactive lysine (OMIU-RL) was calculated from the molar amount of homoarginine and the molecular weight of lysine.

Glucosinolates were quantified according to ISO 9167-1 [16]. Glucosinolates were extracted by a $70 \%$ (v/ v) methanol in water mixture at $70{ }^{\circ} \mathrm{C}$, using sinigrin as internal standard. The glucosinolates were then linked on an anion-exchange column, purified and on-column desulphated by overnight action of sulphatase enzyme. Desulphoderivatives were eluted with water and analyzed using reverse phase liquid chromatography with gradient elution and UV detection at $229 \mathrm{~nm}$.

\section{Differential scanning calorimetry}

Degree of denaturation of the samples was studied using differential scanning calorimetry (DSC12E, MettlerToledo, Greifensee, Switzerland). Samples (15-20 mg) were weighed into medium pressure crucibles (ME-29990, Mettler-Toledo, Greifensee, Switzerland) and approximately $60 \mathrm{mg}$ of demineralized water was added. Samples were left overnight to equilibrate at $4{ }^{\circ} \mathrm{C}$. The heating program ranged from 15 to $120^{\circ} \mathrm{C}$ at a rate of $5{ }^{\circ} \mathrm{C} / \mathrm{min}$, with an initial isothermal step of $5 \mathrm{~min}$ at $15{ }^{\circ} \mathrm{C}$. A crucible filled with demineralized water was used in the reference cell. Enthalpy $(\mathrm{J} / \mathrm{g} \mathrm{CP})$ of denaturation was determined using the TA89E software (Version 3, Mettler-Toledo, Switzerland) for analysis of thermo-analytical data.

\section{Protein solubility}

Protein dispersibility index (PDI) in water was measured using a modification of the method of AOCS [17]. Approximately $75 \mathrm{mg}$ of sample was weighed and mixed for $30 \mathrm{~s}$ with $1.5 \mathrm{~mL}$ of water in a vortex. The sample was then mixed for $20 \mathrm{~min}$ in a rotator SB2 (Stuart-Barloworld Scientific Staffordshire, UK) 
with an angle of $90^{\circ}$ and a speed of $20 \mathrm{rpm}$. Centrifugation was performed at $13,000 \times \mathrm{g}$ for $10 \mathrm{~min}$ at room temperature and the supernatant analyzed for nitrogen content. Soluble protein in $0.2 \%(\mathrm{w} / \mathrm{v})$ $\mathrm{KOH}$, equivalent to nitrogen solubility index (NSI), was measured according to ISO 14244 [18].

\section{Protein secondary structure}

Attenuated total reflectance Fourier transform infrared spectroscopy (ATR-FTIR) (Tensor 27, Bruker, MA, USA) was used to measure the spectra ranging from 600 to $4,000 / \mathrm{cm}$. The spectra were measured as absorbance with a resolution of $4 / \mathrm{cm}$ and using 16 scans per spectra. Spectral measurements were performed in duplicate and corrected for background. The OPUS software Version 7.2 (Bruker, Billerica, MA, USA) was used for all spectral transformations and calculations according to the procedure described by $\mathrm{Hu}$ et al. [19] with minor modifications. Briefly, Fourier self-deconvolution was applied to the Amide I region $(1,595-1,705 / \mathrm{cm})$ of the original spectra, using a Lorentzian correction with a bandwidth of $25 / \mathrm{cm}$ and a noise reduction factor of 0.3 . The second derivative was applied to the original spectra and used for peak selection. Curve fitting of the selected peaks was performed using a Gaussian approximation with the Levenberg-Marquardt algorithm as the fitting method and an iteration time of $10 \mathrm{~s}$. Selected peaks were identified using existing literature $[7,20]$.

\section{In vitro digestibility}

\section{Two-step enzymatic digestibility}

Dry matter and CP digestibility were determined using a modification of the method from Boisen and Fernández [21]. Briefly, $5 \mathrm{~g}$ of material was mixed with $125 \mathrm{~mL}$ of a pH 6.0 disodium phosphate buffer $(0.1 \mathrm{~mol} / \mathrm{L})$ and $50 \mathrm{~mL}$ of $0.2 \mathrm{~mol} / \mathrm{L} \mathrm{HCl}$. This mixture was incubated with $5 \mathrm{~mL}$ of a freshly prepared pepsin solution $(0.025 \mathrm{~g} / \mathrm{mL})$ for $2 \mathrm{~h}$ at $39{ }^{\circ} \mathrm{C}$ and $\mathrm{pH}$ 2.0. After this incubation, $50 \mathrm{~mL}$ of $\mathrm{pH} 6.8$ sodium phosphate buffer $(0.2 \mathrm{~mol} / \mathrm{L})$ and $25 \mathrm{~mL}$ of $0.6 \mathrm{~mol} / \mathrm{L} \mathrm{NaOH}$ were added. The $\mathrm{pH}$ was adjusted to 6.8 , $5 \mathrm{~mL}$ of a freshly prepared pancreatin solution $(0.10 \mathrm{~g} / \mathrm{mL})$ were added and the mixture incubated for $4 \mathrm{~h}$. All buffers and solutions were preheated at $39^{\circ} \mathrm{C}$ before addition, with the exception of the enzyme solutions. After the latter incubation, $5 \mathrm{~mL}$ of a $20 \%(\mathrm{w} / \mathrm{v})$ sulfosalicylic acid solution was added and the mixture centrifuged at $4,500 \times \mathrm{g}$ for $10 \mathrm{~min}$ at room temperature. The insoluble residue was collected, freeze-dried and analyzed for dry matter and nitrogen content.

\section{pH-STAT enzymatic hydrolysis}

Enzymatic hydrolysis was performed with the addition of porcine trypsin, bovine chymotrypsin and porcine intestinal peptidase using a modification of the $\mathrm{pH}$ -
STAT method from Pedersen and Eggum [22]. In contrast to the original method, the hydrolysis was extended for 120 min after the addition of the enzymes. The volume of $0.1 \mathrm{~mol} / \mathrm{L} \mathrm{NaOH}$ added was used for the calculation of the degree of hydrolysis (DH) according to Eq. 1:

$$
\mathrm{DH}=(V b \times N b) /(\alpha \times m p \times \text { htot })
$$

in which $\mathrm{Vb}$ is the volume of $\mathrm{NaOH}$ solution added, $\mathrm{Nb}$ is the normality of the titration solution, $\alpha$ is the degree of dissociation of the $\alpha-\mathrm{NH}_{2}$ group (i.e. 0.794 at $37{ }^{\circ} \mathrm{C}$ and $\mathrm{pH} 8), m p$ is the mass of protein in grams and htot the total number of peptide bonds per gram of substrate (7.8 eq/g). The DH was used to calculate the rate of protein hydrolysis $(k)$ based on the model described by Butré et al. [23] shown in Eq. 2:

$$
\mathrm{DH}=1 / b \times \ln (k \times h t+1)
$$

In this model $b$ is a parameter that defines the shape of the curve, $k$ is the constant for the rate of protein hydrolysis (/s) and $h t$ is the hydrolysis time (s). The model was fitted using the MODEL procedure of SAS software (Version 9.3, SAS Institute Inc., Cary, NC).

\section{Calculations and statistical analysis}

Degradation rate constants and half-life for the parameters were calculated according to first-order reactions which were selected after fitting zero and second order reactions. Regression equations for the effect of toasting time were generated using the GLM procedure of the statistical software SAS. Correlations between parameters related to protein changes (e.g. NSI, PDI, lysine and OMIURL content, secondary structure) and in vitro digestibility (e.g. CP digestibility, DH after $120 \mathrm{~min}, k$ ) were determined using the CORR procedure of SAS software. Linear or quadratic effects were considered as significant when the $P$-values were lower than 0.05 and as trends when $P$-values were between 0.05 and 0.10. The experimental unit was the RSM at each toasting time point.

\section{Results}

During the oil extraction process of the rapeseed seeds, the crude fat content was reduced from $493 \mathrm{~g} / \mathrm{kg} \mathrm{DM}$ in the seeds to $16 \mathrm{~g} / \mathrm{kg}$ DM in the untoasted meal (Table 1). At the same time, the NSI was decreased from $86.9 \%$ in the seed to $79.9 \%$ in the untoasted meal.

There was no effect of toasting time on the $\mathrm{CP}$ content of RSM, whilst there was a linear increase $(P=0.02)$ of the DM content with increasing toasting time (Table 1 ). There was a $33 \%$ linear increase $(P<0.001)$ in the NDF content with increasing toasting time from the untoasted to the $120 \mathrm{~min}$ toasted RSM. In contrast, the ADF 
Table 1 Characterization of rapeseed samples before and after toasting ${ }^{a}$

\begin{tabular}{|c|c|c|c|c|c|c|c|c|c|}
\hline Material & $\begin{array}{l}\mathrm{DM} \\
\mathrm{g} / \mathrm{kg}\end{array}$ & $\begin{array}{l}\mathrm{CP}, \mathrm{g} / \mathrm{kg} \\
\mathrm{DM}\end{array}$ & $\begin{array}{l}\text { Crude fat, } \\
\text { g/kg DM }\end{array}$ & $\begin{array}{l}\text { NDF, g/kg } \\
\text { DM }\end{array}$ & $\begin{array}{l}\text { ADF, g/kg } \\
\text { DM }\end{array}$ & $\begin{array}{l}\text { ADIN, g/kg } \\
\text { DM }\end{array}$ & $\begin{array}{l}\text { Denaturation } \\
\text { enthalpy, J/g CP }\end{array}$ & $\begin{array}{l}\mathrm{NSI}, \mathrm{g} / \mathrm{kg} \\
\mathrm{CP}\end{array}$ & $\begin{array}{l}\mathrm{PDI}, \mathrm{g} / \mathrm{kg} \\
\mathrm{CP}\end{array}$ \\
\hline Rapeseed & 937 & - & 493 & - & - & - & 2.23 & 869 & - \\
\hline Dried rapeseed & 947 & - & 489 & - & - & - & - & 861 & - \\
\hline Rapeseed cake & 923 & - & 135 & - & - & - & - & 861 & - \\
\hline RSM + solvent & 907 & - & 13 & - & - & - & - & 825 & - \\
\hline \multicolumn{10}{|c|}{ Toasting time RSM } \\
\hline $0 \mathrm{~min}$ & 913.0 & 360.0 & 16 & 274.4 & 217.4 & 3.0 & 2.34 & 799.0 & 260.7 \\
\hline $20 \mathrm{~min}$ & 917.7 & 362.0 & - & 278.2 & 211.7 & 3.0 & 1.29 & 695.5 & 161.8 \\
\hline $40 \mathrm{~min}$ & 918.9 & 366.3 & - & 291.4 & 215.5 & 3.1 & 1.23 & 597.5 & 129.3 \\
\hline $60 \mathrm{~min}$ & 922.8 & 372.9 & - & 319.1 & 213.3 & 3.1 & 1.13 & 537.0 & 105.3 \\
\hline $80 \mathrm{~min}$ & 924.6 & 368.4 & - & 338.9 & 216.0 & 3.3 & 1.07 & 513.0 & 84.7 \\
\hline $100 \mathrm{~min}$ & 917.8 & 363.7 & - & 354.6 & 217.1 & 3.4 & 1.03 & 475.5 & 72.6 \\
\hline $120 \mathrm{~min}$ & 930.8 & 369.1 & - & 365.3 & 218.2 & 3.8 & 0.74 & 431.0 & 63.3 \\
\hline SEM & 1.7 & 1.4 & & 9.8 & 1.1 & 0.3 & 0.11 & 31 & 15 \\
\hline \multicolumn{10}{|l|}{$P$-value } \\
\hline Linear & 0.02 & 0.19 & - & $<0.001$ & 0.21 & $<0.001$ & 0.02 & $<0.001$ & $<0.001$ \\
\hline Quadratic & 0.90 & 0.15 & - & 0.91 & 0.40 & 0.02 & 0.07 & $<0.001$ & $<0.001$ \\
\hline
\end{tabular}

${ }^{a} D M$ dry matter, $C P$ crude protein, NDF neutral detergent fiber, $A D F$ acid detergent fiber, $A D I N$ nitrogen linked to the acid detergent fiber, $N S I$ nitrogen solubility index, $P D I$ protein dispersibility index, $R S M$ rapeseed meal, SEM standard error of the mean

content was not affected $(P>0.05)$ by toasting time. Linear $(P<0.001)$ and quadratic $(P=0.02)$ effects of toasting time were found on the content of ADIN. The increase in the content of ADIN was more evident after 60 min toasting. Toasting time had a linear effect $(P=$ $0.02)$ and a tendency for a quadratic effect $(P=0.07)$ on the denaturation enthalpy, which decreased with increasing toasting time. There were linear $(P<0.001)$ and quadratic $(P<0.001)$ effects of toasting time on NSI and PDI, with more apparent effects at low toasting times.

\section{Glucosinolates content}

There were linear and quadratic effects of toasting time on the content of total $(P=0.001)$, alkenyl $(P<0.01)$ and indolyl plus aralkyl $(P<0.001)$ glucosinolates $($ Table 2$)$. The largest decrease seems to occur after $60-80 \mathrm{~min}$ of toasting. Not all the glucosinolate types, however, responded to toasting in the same manner. Whilst the contents of epi-progoitrin, sinalbin and neoglucobrassicin were linearly reduced $(P<0.001)$ with increased toasting times, the effect of toasting time was both linear

Table 2 Content ( $\mu \mathrm{mol} / \mathrm{g} \mathrm{DM})$ of glucosinolates in rapeseed meal samples toasted for different times ${ }^{\mathrm{a}}$

\begin{tabular}{|c|c|c|c|c|c|c|c|c|c|c|c|c|c|}
\hline Toasting time & PRO & EPRO & GNL & GNA & GBN & SNB & GST & 4-OHGBS & GBS & NGBS & Alk & Ara + Ind & Total \\
\hline $0 \min$ & 12.62 & 0.36 & 0.81 & 4.83 & 2.66 & 0.23 & 0.63 & 5.50 & 0.23 & 0.11 & 21.28 & 6.70 & 27.98 \\
\hline $20 \mathrm{~min}$ & 10.18 & 0.28 & 0.68 & 4.01 & 2.08 & 0.25 & nd & 2.69 & 0.18 & 0.09 & 17.21 & 3.20 & 20.41 \\
\hline $40 \mathrm{~min}$ & 8.15 & 0.25 & 0.56 & 3.22 & 1.67 & 0.18 & nd & 1.39 & 0.13 & 0.08 & 13.83 & 1.77 & 15.60 \\
\hline $60 \mathrm{~min}$ & 5.94 & 0.16 & 0.41 & 2.47 & 1.11 & 0.16 & nd & 0.58 & 0.09 & 0.06 & 10.09 & 0.89 & 10.97 \\
\hline $80 \mathrm{~min}$ & 3.84 & 0.06 & 0.28 & 1.65 & 0.71 & nd & nd & 0.20 & 0.06 & nd & 6.52 & 0.26 & 6.78 \\
\hline $100 \mathrm{~min}$ & 2.27 & nd & 0.19 & 0.99 & 0.36 & 0.03 & nd & 0.06 & nd & nd & 3.81 & 0.08 & 3.89 \\
\hline $120 \mathrm{~min}$ & 1.13 & 0.02 & 0.13 & 0.46 & 0.20 & nd & nd & nd & nd & nd & 1.94 & 0.00 & 1.94 \\
\hline SEM & 1.05 & 0.04 & 0.06 & 0.40 & 0.23 & 0.03 & - & 0.45 & 0.02 & 0.01 & 1.78 & 0.54 & 2.28 \\
\hline \multicolumn{14}{|l|}{$P$-value } \\
\hline Linear & $<0.001$ & $<0.001$ & $<0.001$ & $<0.001$ & $<0.001$ & $<0.001$ & - & $<0.001$ & $<0.001$ & $<0.001$ & $<0.001$ & $<0.001$ & $<0.001$ \\
\hline Quadratic & 0.001 & 0.19 & 0.006 & 0.04 & 0.003 & 0.73 & - & $<0.001$ & 0.01 & 0.55 & 0.002 & $<0.001$ & $<0.001$ \\
\hline
\end{tabular}


and quadratic $(P<0.05)$ for the other glucosinolates. The most abundant alkenyl glucosinolates was progoitrin (Table 2) which, even after toasting for $120 \mathrm{~min}$, remained present at $9 \%$ of its content in the untoasted RSM. Gluconapoleiferin was the most resilient alkenyl glucosinolate after toasting, as $16 \%$ of the content of the untoasted RSM can still be found after 120 min toasting.

\section{Amino acids content}

The amino acid content is reported in Table 3. There was a linear decrease $(P<0.05)$ in the content of alanine, aspartic acid, glutamic acid and glycine with increasing toasting time. Increasing toasting time also caused a linear decrease $(P<0.001)$ of the lysine and arginine content. Arginine and lysine contents were reduced by 7 and $23 \%$, respectively, after toasting for $120 \mathrm{~min}$ in comparison with the untoasted RSM. The content of OMIU-RL was also reduced $(P<0.001)$ linearly with increasing toasting time. After $120 \mathrm{~min}$ of toasting, the OMIU-RL content was $38 \%$ lower than that in the untoasted sample. The reduction of the OMIU-RL content after toasting was more pronounced than the reduction of the lysine content. This is reflected in the reduction of the OMIU-RL to lysine ratio from 0.98 in the untoasted RSM sample to 0.80 in the RSM toasted for $120 \mathrm{~min}$.

\section{Secondary protein structure}

The proportion of intermolecular $\beta$-sheets tended $(P=$ $0.06)$ to be affected by the quadratic effect of toasting time (Table 4). This proportion markedly increased after the initial $20 \mathrm{~min}$ of toasting and thereafter gradually decreased with longer toasting times. In contrast, the proportion of $\alpha$-helix decreased by half after the initial 20 min of toasting and increased thereafter with toasting time from $16.2 \%$ after $20 \mathrm{~min}$ to $19.7 \%$ after $120 \mathrm{~min}$ toasting. Toasting time had a quadratic effect $(P=0.04)$ on the $\alpha$-helix proportion. Linear $(P=0.04)$ and quadratic $(P=0.01)$ effects of toasting time were noticed on the T2 proportion. This element increased after the first $20 \mathrm{~min}$ toasting, but stabilize thereafter. Linear $(P<0.001)$ and quadratic $(P=0.004)$ effects of toasting time were also found for the proportion of A2 elements (Table 4). The increase in these elements was more apparent after the first 20 min of toasting than thereafter.

\section{Degradation rate constants}

Indolyl, alkenyl and total glucosinolates had the highest degradation rate constants and the shortest half-life compared to the other parameters (Table 5). The degradation rate constant of indolyl glucosinolates was 2fold higher than that of alkenyl glucosinolates. The half-life of total glucosinolates was approximately 5.5fold lower than that of OMIU-RL and 10-fold lower than that of lysine. The degradation rate constant of OMIU-RL was almost twice that of lysine. The NSI had a degradation rate constant 2-fold as low as that of PDI, which is also reflected in a longer half-life.

\section{In vitro $\mathrm{CP}$ digestibility}

With the two-step enzymatic digestibility method, there was a tendency $(P=0.08)$ for a linear increase of the in vitro dry matter digestibility along with toasting time (Table 6). In addition, there was a quadratic effect of toasting time on the in vitro $\mathrm{CP}$ digestibility $(P=0.005)$, increasing before $60 \mathrm{~min}$ of toasting and decreasing thereafter. With the pH-STAT enzymatic hydrolysis

Table 3 Amino acid contents ( $\mathrm{g} / 16 \mathrm{~g} \mathrm{~N}$ ) and ratio between OMIU-RL and lysine in rapeseed meal samples toasted for different times $^{\mathrm{a}}$

\begin{tabular}{|c|c|c|c|c|c|c|c|c|c|c|c|c|c|c|c|c|}
\hline \multirow{2}{*}{$\begin{array}{l}\text { Toasting } \\
\text { time }\end{array}$} & \multicolumn{10}{|c|}{ Indispensable amino acids } & \multicolumn{6}{|c|}{ Dispensable amino acids } \\
\hline & Arg & His & Ile & Leu & Lys & OMIU-RL & Phe & Thr & Val & Ratio & Ala & Asp & Glu & Gly & Ser & Tyr \\
\hline $0 \mathrm{~min}$ & 5.47 & 2.93 & 4.11 & 7.04 & 6.31 & 6.20 & 4.07 & 4.67 & 5.38 & 0.98 & 4.63 & 7.38 & 17.34 & 5.33 & 4.48 & 3.30 \\
\hline $20 \min$ & 5.50 & 2.95 & 4.17 & 7.13 & 6.08 & 5.66 & 4.12 & 4.70 & 5.43 & 0.93 & 4.68 & 7.39 & 17.45 & 5.38 & 4.56 & 3.34 \\
\hline $40 \mathrm{~min}$ & 5.42 & 2.93 & 4.13 & 7.06 & 5.83 & 5.32 & 4.06 & 4.67 & 5.38 & 0.91 & 4.64 & 7.35 & 17.30 & 5.33 & 4.51 & 3.26 \\
\hline $60 \mathrm{~min}$ & 5.18 & 2.85 & 4.03 & 6.90 & 5.46 & 4.85 & 3.97 & 4.55 & 5.28 & 0.89 & 4.53 & 7.15 & 16.83 & 5.19 & 4.39 & 3.17 \\
\hline $80 \mathrm{~min}$ & 5.23 & 2.91 & 4.08 & 6.97 & 5.39 & 4.61 & 4.03 & 4.59 & 5.34 & 0.86 & 4.58 & 7.21 & 17.05 & 5.25 & 4.45 & 3.24 \\
\hline $100 \min$ & 5.25 & 3.01 & 4.18 & 7.15 & 5.23 & 4.22 & 4.12 & 4.68 & 5.47 & 0.81 & 4.69 & 7.36 & 17.40 & 5.38 & 4.55 & 3.27 \\
\hline $120 \mathrm{~min}$ & 5.08 & 2.94 & 4.09 & 6.99 & 4.85 & 3.86 & 4.02 & 4.61 & 5.38 & 0.80 & 4.60 & 7.18 & 17.06 & 5.27 & 4.47 & 3.23 \\
\hline SEM & 0.04 & 0.01 & 0.02 & 0.03 & 0.13 & 0.21 & 0.02 & 0.02 & 0.02 & 0.02 & 0.02 & 0.03 & 0.07 & 0.02 & 0.02 & 0.02 \\
\hline \multicolumn{17}{|l|}{$P$-value } \\
\hline Linear & $<0.001$ & 0.09 & 0.09 & 0.15 & $<0.001$ & $<0.001$ & 0.37 & 0.15 & 0.07 & $<0.001$ & 0.05 & 0.02 & 0.03 & 0.04 & 0.06 & 0.35 \\
\hline Quadratic & 0.72 & 0.24 & 0.23 & 0.24 & 0.74 & 0.32 & 0.29 & 0.17 & 0.17 & 0.92 & 0.14 & 0.30 & 0.16 & 0.16 & 0.12 & 0.16 \\
\hline
\end{tabular}

${ }^{\mathrm{a}}$ Arg arginine, His histidine, Ile isoleucine, Leu leucine, Lys lysine, OMIU-RL O-methylisourea reactive lysine, Phe phenylalanine, Thr threonine, Val valine, Ratio ratio OMIU-RL to lysine, Ala alanine, Asp aspartic acid, Glu glutamic acid, Gly glycine, Ser serine, Tyr tyrosine, SEM standard error of the mean 
Table 4 Proportion (\%) of the secondary structures of rapeseed meals toasted for different times ${ }^{a}$

\begin{tabular}{|c|c|c|c|c|c|c|}
\hline $\begin{array}{l}\text { Toasting } \\
\text { time }\end{array}$ & $\begin{array}{l}\text { Intermolecular } \beta \text {-sheets } \\
(1,627-1,630 / \mathrm{cm})^{\mathrm{b}}\end{array}$ & $\begin{array}{l}\text { Intramolecular } \beta \text {-sheets } \\
(1,634-1,635 / \mathrm{cm})\end{array}$ & $\begin{array}{l}\text { a-helix } \\
(1,655-1,656 / \mathrm{cm})\end{array}$ & $\begin{array}{l}\text { T2 } \\
(1,674 / \mathrm{cm})\end{array}$ & $\begin{array}{l}\text { A2 } \\
(1,692 / \mathrm{cm})\end{array}$ & a-helix : $\beta$-sheet \\
\hline $0 \mathrm{~min}$ & 49.0 & 5.5 & 30.5 & 8.9 & 6.1 & 0.62 \\
\hline $20 \mathrm{~min}$ & 63.1 & nd & 16.2 & 13.7 & 6.9 & 0.26 \\
\hline $40 \mathrm{~min}$ & 60.8 & nd & 17.5 & 14.4 & 7.2 & 0.29 \\
\hline $60 \mathrm{~min}$ & 60.0 & nd & 18.0 & 14.6 & 7.4 & 0.30 \\
\hline $80 \mathrm{~min}$ & 59.4 & nd & 18.0 & 15.0 & 7.5 & 0.30 \\
\hline $100 \mathrm{~min}$ & 57.5 & nd & 20.4 & 14.6 & 7.5 & 0.36 \\
\hline $120 \mathrm{~min}$ & 57.9 & nd & 19.7 & 14.7 & 7.7 & 0.34 \\
\hline SEM & 1.0 & - & 1.1 & 0.5 & 0.1 & 0.03 \\
\hline \multicolumn{7}{|l|}{$P$-value } \\
\hline Linear & 0.94 & - & 0.63 & 0.04 & $<0.001$ & 0.56 \\
\hline Quadratic & 0.06 & - & 0.04 & 0.01 & 0.004 & 0.03 \\
\hline
\end{tabular}

${ }^{a} T 2$ turns, $A 2$ intermolecular hydrogen-bonded $\beta$-sheets, nd not detected, SEM standard error of the mean

${ }^{\mathrm{b}}$ Regions of the Fourier transform infrared spectra

method, there were no effects of toasting time on the $\mathrm{DH}$ after 120 min hydrolysis. However, the rate of protein hydrolysis was linearly $(P<0.001)$ reduced with increasing toasting time.

The in vitro CP digestibility with the two-step enzymatic method did not correlate with any of the parameters of protein changes measured. In contrast, significant correlations were found between $k$ and NSI $(r=0.88, P<0.001)$, PDI $(r=0.79, P=0.001)$, lysine $(r$ $=0.92, \quad P<0.001)$, OMIU-RL content $(r=0.91, \quad P<$ $0.001)$, and the proportion of $\mathrm{A} 2$ in the secondary structure $(r=-0.74, P=0.004)$. Significant correlations were also found between the DH after 120 min hydrolysis and the proportion of intermolecular $\beta$-sheets $(r=-0.66, P=0.01), \alpha$-helices $(r=0.60, P=0.03)$ and the ratio of $\alpha$-helices to $\beta$-sheets $(r=0.58, P=0.04)$ in the secondary structure.

Table 5 Degradation rate constants and half-life (first order reactions) of parameters measured after toasting of rapeseed meal ${ }^{a}$

\begin{tabular}{lcl}
\hline Parameter & $\begin{array}{l}\text { Degradation rate constant, } \\
\times 10^{-3} / \mathrm{min}\end{array}$ & Half-life, min \\
\hline Enthalpy of denaturation & 6.1 & 114 \\
$\mathrm{NSI}$ & 4.8 & 144 \\
$\mathrm{PDI}$ & 10.6 & 65 \\
Alkenyl glucosinolates & 20.4 & 34 \\
Indolyl glucosinolates & 44.3 & 16 \\
Total glucosinolates & 22.3 & 31 \\
Arginine & 0.7 & 990 \\
Lysine & 2.1 & 330 \\
OMIU-reactive lysine & 3.8 & 182 \\
\hline
\end{tabular}

${ }^{\mathrm{a}} \mathrm{NSI}$ nitrogen solubility index, $P D /$ protein dispersibility index

\section{Discussion}

The small reduction in the enthalpy of denaturation and the NSI, along with a high ratio of OMIU-RL to total lysine (0.98) in the untoasted RSM can be considered indicators of a RSM with low protein denaturation and high protein nutritional quality. A decrease in protein solubility in heat-treated materials is an indication of the aggregation of proteins after denaturation [24, 25]. As more proteins become denatured and unfolded with increasing toasting time, intra and intermolecular interactions within and between proteins promote aggregation.

Both NSI and PDI have been used before as indicators of the extent of thermal damage in processed proteinrich ingredients (e.g. soybean meal and RSM) [26-28]. Protein solubility and the standardized ileal digestibility of AA in cecectomized broilers were reduced with increasing autoclaving time of a commercial RSM [28]. Pastuszewska et al. [29] suggested that rapeseed meals with a NSI in $0.5 \% \mathrm{KOH}$ between 55 and $60 \%$ can be considered of a high nutritional value. These values were achieved in our experiment between 40 and $60 \mathrm{~min}$ toasting, which correspond to toasting times used during commercial RSM production [29].

The increasing NDF and ADIN contents with increasing toasting time in the present experiment was previously described after hydrothermal treatments of canola and RSM $[8,29,30]$. These authors, however, also reported an increase in the ADF content, which was not found in the present study. The difference in the results could be due to milder conditions used in the present experiment compared to those reported previously. The increase of the ADIN content was linked to a decrease of the standardized ileal protein digestibility and was proposed as a good indicator for protein damage [30]. Although it has been suggested that heat treatment 
Table 6 Coefficients of in vitro digestibility and hydrolysis of rapeseed meal samples toasted for different times ${ }^{a}$

\begin{tabular}{|c|c|c|c|c|}
\hline \multirow[t]{2}{*}{ Toasting time } & \multicolumn{2}{|c|}{ Two-step enzymatic digestibility } & \multicolumn{2}{|c|}{ pH-STAT enzymatic hydrolysis } \\
\hline & $\mathrm{CDMD}$ & CCPD & $\mathrm{DH} 120 \mathrm{~min}$ & $k(/ s)$ \\
\hline $0 \mathrm{~min}$ & 0.382 & 0.752 & 0.186 & 0.029 \\
\hline $20 \mathrm{~min}$ & 0.393 & 0.758 & 0.173 & 0.032 \\
\hline $40 \mathrm{~min}$ & 0.406 & 0.773 & 0.179 & 0.027 \\
\hline $60 \mathrm{~min}$ & 0.418 & 0.776 & 0.175 & 0.024 \\
\hline $80 \mathrm{~min}$ & 0.415 & 0.764 & 0.183 & 0.018 \\
\hline $100 \mathrm{~min}$ & 0.411 & 0.753 & 0.179 & 0.017 \\
\hline $120 \mathrm{~min}$ & 0.415 & 0.750 & 0.185 & 0.013 \\
\hline SEM & 0.005 & 0.003 & 0.002 & 0.002 \\
\hline \multicolumn{5}{|l|}{$P$-value } \\
\hline Linear & 0.08 & 0.32 & 0.23 & $<0.001$ \\
\hline Quadratic & 0.19 & 0.005 & 0.18 & 0.47 \\
\hline
\end{tabular}

${ }^{a} C D M D$ coefficient of dry matter digestibility, CCPD coefficient of crude protein digestibility, $D H$ degree of hydrolysis, SEM standard error of the mean

increases the linkage between proteins and fiber [29], it is possible that the increase in the content of NDF, ADF and ADIN results from the inability of the solvents used to solubilize the aggregated and chemically modified proteins (e.g. melanoidins) [30].

The changes observed in protein denaturation and solubility with increasing toasting time do not parallel the changes observed in the secondary structure of proteins. Contrary to what we expected, there was an increase in the proportion of $\alpha$-helix and a decrease of intermolecular $\beta$-sheets with increasing toasting time after the initial 20 min of toasting. Previous research $[7,20]$ described a decrease in the proportion of $\alpha$-helix and an increase in that of intermolecular $\beta$-sheet structures after thermal treatment, which was also expected in the present experiment with increasing toasting time. The increase in the proportion of intermolecular $\beta$-sheets was linked to a decrease in the in vitro CP digestibility [7]. It is possible that with increasing denaturation, which is the rate limiting step, there is partial unfolding of the proteins with a simultaneous increase of aggregation and (partial) refolding of the secondary structure. Most of the literature on thermal-induced changes to the secondary structure of proteins reports the effects after a certain period of time (e.g. autoclaving at $120{ }^{\circ} \mathrm{C}$ for $20 \mathrm{~min}$ ) [7, 20, 31], but do not include the changes occurring during that time period. When considering all time points analyzed in the present study, the net results for secondary structure are still comparable to the results described in literature after autoclaving $[7,20,31]$. The presence of A2 bands has been related to aggregation of proteins due to intermolecular hydrogen-bonded anti-parallel $\beta$-sheets [32] or to absorption of infrared light from the amino acid side chains [7].

The formation of Maillard reaction products (MRP) results from chemical changes to $\mathrm{AA}$, for which the most susceptible ones are lysine and arginine [33]. With increasing toasting time, chemical changes of AA continue to occur resulting in the formation of more early MRP and the conversion of the early into advanced MRP and melanoidins [33]. In contrast to early MRP, advanced MRP cannot be reverted into lysine under conditions of $6 \mathrm{~mol} / \mathrm{L}$ acid hydrolysis [15]. This was noticed by a decrease of lysine content with increasing toasting time. The decrease of the OMIU-RL to lysine ratio is probably the result of higher rate of formation of early MRP compared to advanced ones. Previous research only showed a reduction in the ratio between lysine and reactive lysine after $64 \mathrm{~min}$ of toasting [8]. This might be due to the low reactive lysine to lysine ratio determined already in the rapeseed cake (i.e. 0.81). In a recent experiment [3], values of lysine for commercial RSM of German oil mills ranged from 5.5 to $5.3 \mathrm{~g} / 100 \mathrm{~g} \mathrm{CP}$, which correspond in our experiment to toasting times of approximately 71 and $91 \mathrm{~min}$, respectively. However, in that same experiment, the OMIU-RL content ranged from 4.4 to $4.0 \mathrm{~g} / 16 \mathrm{~g} \mathrm{~N}$ for the same RSM. This makes the ratio of OMIU-RL to lysine much lower compared to those reported here. The variation in the results could be due to the shorter incubation times for the reaction with OMIU used in the those studies $[3,8]$ compared to the longer incubation times used in the present study $(2-2.5$ vs. $7 \mathrm{~d})$. It is possible that proteins with a large extent of thermal damage and high aggregation (low solubility) might need longer incubation times for the OMIU reactive to penetrate within the aggregate structure and bind with the free lysine. Alternatively, free lysine may have been formed during toasting, which cannot be analyzed by the OMIU-RL procedure.

The decrease in the ratio lysine to $\mathrm{CP}$ with thermal treatments has been reported before [8, 30, 34-36]. According to these authors, lower ratios, as compared to higher ones, indicate that protein damage occurred due to the 
formation of MRP. A decrease of this ratio led to a decrease of the ileal digestibility of CP and AA $[8,30,34]$. Therefore, the decrease in the lysine to $\mathrm{CP}$ ratio reported in our experiment with increasing toasting time is indicative of protein damage and could lead to a decrease of the in vivo protein digestibility. The ratio lysine to $\mathrm{CP}$ of the 0 min toasted RSM in the present study (6.3 g lysine/100 g $\mathrm{CP})$ corresponds well to values previously reported for non-toasted canola meal [36]. The apparent ileal digestibility of lysine of the non-toasted canola meal in broilers ranged from 87 to $92 \%$ [36]. A lower ratio of lysine to CP (5.55 g lysine/100 g CP) was reported in that study for solvent-extracted canola meals from 7 different production plants. The apparent ileal digestibility of lysine for the solvent-extracted canola meals was lower and more variable (ranging from 65.5 to $85.7 \%$ ) than the values reported for non-toasted canola meal [36]. Other authors [8, 30] have reported lysine to CP ratios of $5.2 \mathrm{~g} / 100 \mathrm{~g} \mathrm{CP}$ in commercial canola meals and $5.1 \mathrm{~g} / 100 \mathrm{~g}$ CP in RSM toasted for $48 \mathrm{~min}$, indicating damage of the proteins. These values corresponded to standardized ileal digestibilities of lysine in growing pigs of 68.2 and $64 \%$, respectively. In the present experiment, values of lysine to $\mathrm{CP}$ ratio that resemble the ones reported by these authors were obtained after $100 \mathrm{~min}$ toasting, indicating that the thermal treatments applied by these authors were likely more severe than the ones used herein.

First order reactions have been used previously to model the decrease in glucosinolate content of red cabbage [37] and reactive (available) lysine in model systems [38]. One of the aims of toasting during the production of RSM is to inactivate the glucosinolates without affecting the nutritional quality of proteins (e.g. lysine content). Glucosinolates were degraded at a faster rate than the degradation of OMIU-RL and lysine. Furthermore, the rate constant of decrease of the solubility parameters (i.e. NSI and PDI) is higher than that of OMIU-RL and lysine. This could be an indication that changes in the structure of proteins occur earlier during toasting than chemical (i.e. Maillard) changes. The higher rate constant of decrease of PDI could make it a better indicator of the changes in solubility after toasting of RSM than NSI. Previous research in soybeans indicated that PDI reflects protein quality better than NSI, especially after processing at mild conditions [39].

The range of values obtained with the two-step in vitro $\mathrm{CP}$ digestibility can be considered as narrow (75.0$77.6 \%)$. A linear decrease of the in vitro $\mathrm{CP}$ digestibility from $71 \%$ in the 48 min toasted RSM to $62 \%$ in the 93 min toasted meal was reported in a recent study [8]. This also matched the reported decrease in standardized ileal CP digestibility in that study. Toasting time did not affect the DH after 120 min indicating that the observed protein changes are not a restriction for protein hydrolysis when the enzymes are available sufficiently long to hydrolyze. However, the rate at which the enzymes access the substrate during hydrolysis was linearly reduced by toasting time. A reduction in the rate of hydrolysis with increasing heating time has been reported before [40] for glycinin from soybeans. The high correlation of the rate of hydrolysis with protein solubility (in alkali and water), and lysine or OMIU-RL contents could explain the decrease in the rate of hydrolysis with increasing toasting time. It is not possible, however, to distinguish if the formation of aggregates (i.e. lower solubility) or the chemical modification of the Maillard-sensitive AA is the major factor controlling the rate of hydrolysis, as both occur simultaneously during toasting. The decrease in the rate of protein hydrolysis with increasing toasting time could explain the reduction of the ileal protein digestibility reported in other studies after toasting $[5,8]$.

Extensive reviews have suggested inclusion levels of total glucosinolates ranging from 2 to $2.5 \mu \mathrm{mol} / \mathrm{g}$ diet for pigs, whilst for poultry, the inclusion level ranges from 2 to $10 \mu \mathrm{mol} / \mathrm{g}$ diet $[41,42]$. To maintain these total glucosinolates level, at the maximum rate of protein hydrolysis (i.e. $20 \mathrm{~min}$ of toasting) in this study, the inclusion level of RSM in the diets for pigs and poultry can be 9.8 and $49 \%$, respectively. This would also involve a loss of $4 \%$ lysine and $9 \%$ OMIU-RL with respect to the untoasted RSM. At the maximum in vitro $\mathrm{CP}$ digestibility (i.e. $60 \mathrm{~min}$ of toasting) in this study, the inclusion level in the diets for pigs can increase to $18.2 \%$, whilst there would be no limit to the inclusion level for poultry diets. This would involve a loss of $13 \%$ lysine and $22 \%$ OMIU-RL with respect to the untoasted RSM. However, the inclusion level of rapeseed or canola meal in the diets for pigs might depend not only on the content of total glucosinolates, but also on the type of glucosinolates included [43]. Whilst the feed intake of weanling pigs did not decrease after the inclusion of $2.2 \mu \mathrm{mol} / \mathrm{g}$ diet of total glucosinolates from Brassica napus [44], the inclusion of $2.2 \mu \mathrm{mol} / \mathrm{g}$ diet of total glucosinolates from Brassica juncea in diets for growingfinishing pigs resulted in a decrease of feed intake and weight gain [43]. The major glucosinolate in B. juncea is gluconapin, whilst B. napus contains higher levels of progoitrin than gluconapin [45].

\section{Conclusions}

Toasting of RSM for increasing time induces physical and chemical changes to the proteins and affects its nutritional value. These changes are correlated to the rate of protein hydrolysis but not the in vitro $\mathrm{CP}$ digestibility or the extent of hydrolysis. Degradation of glucosinolates occurs earlier during toasting and at higher rates than that of OMIU-RL and lysine. 


\section{Abbreviations}

AA: Amino acids; CP: Crude protein; DH: Degree of hydrolysis; DM: Dry matter; MRP: Maillard reaction products; NSI: Nitrogen solubility index; OMIU: Omethylisourea; PDI: Protein dispersibility index; RSM: Rapeseed meal

\section{Funding}

The authors gratefully acknowledge the financial support from the Wageningen UR "IPOP Customized Nutrition" programme financed by Wageningen UR, the Dutch Ministry of Economic Affairs, WIAS, Agrifirm Innovation Center, ORFFA Additives BV, Ajinomoto Eurolysine s.a.s and Stichting VICTAM BV. SSV acknowledges the support from the Universidad de Costa Rica.

\section{Authors' contributions}

SSV, EMAMB, PC, AQ and AFBvdP conceived and designed the experiment. PC and $A Q$ performed the production of the experimental samples. $H G$, EMAMB and AFBvdP supervised the experimental work. SSV performed all chemical analyses and wrote the manuscript. EMAMB, AFBvdP, HG and WHH checked the results and revised the manuscript. All authors read and approved the final manuscript.

\section{Competing interests}

The authors declare that they have no competing interests.

\section{Author details}

'Wageningen Livestock Research, P.O. Box 338, 6700 AH Wageningen, The Netherlands. ${ }^{2}$ Animal Nutrition Group, Wageningen University \& Research, P.O. Box 338, 6700 AH Wageningen, The Netherlands. ${ }^{3}$ Agrifirm Innovation Center, Royal Dutch Agrifirm Group, P.O. Box 20018, 7302 HA Apeldoorn, The Netherlands. ${ }^{4}$ Laboratory of Food Chemistry, Wageningen University \& Research, P.O. Box 17, 6700 AA Wageningen, The Netherlands. ${ }^{5} \mathrm{CREOL} /$ OLEAD, 11 rue Monge, Parc Industriel, 33600 Pessac, France. ${ }^{6} T e r r e s$ Inovia, 11 rue Monge, Parc Industriel, 33600 Pessac, France.

Received: 24 March 2016 Accepted: 29 September 2016

\section{Published online: 18 October 2016}

\section{References}

1. Carré P, Pouzet A. Rapeseed market, worldwide and in Europe. OCL. 2014; 21:D102.

2. Kracht W, Danicke S, Kluge H, Keller K, Matzke W, Hennig U, et al. Effect of dehulling of rapeseed on feed value and nutrient digestibility of rape products in pigs. Arch Anim Nutr. 2004;58:389-404.

3. Messerschmidt U, Eklund M, Sauer N, Rist VTS, Rosenfelder P, Spindler HK, et al. Chemical composition and standardized ileal amino acid digestibility in rapeseed meals sourced from German oil mills for growing pigs. Anim Feed Sci Technol. 2014;187:68-76.

4. Classen HL, Newkirk RW, Maenz DD. Effects of conventional and novel processing on the feed value of canola meal for poultry. In Proc Aust Poult Sci Sym; 9-11 February; Sydney, New South Wales, Australia: 2004. pp. 1-8

5. Newkirk RW, Classen HL, Edney MJ. Effects of prepress-solvent extraction on the nutritional value of canola meal for broiler chickens. Anim Feed Sci Technol. 2003;104:111-9.

6. Gerrard JA, Lasse M, Cottam J, Healy JP, Fayle SE, Rasiah I, et al. Aspects of physical and chemical alterations to proteins during food processing some implications for nutrition. Br J Nutr. 2012;108 Suppl 2:S288-97.

7. Carbonaro M, Maselli P, Nucara A. Relationship between digestibility and secondary structure of raw and thermally treated legume proteins: a Fourier transform infrared (FT-IR) spectroscopic study. Amino Acids. 2012;43:911-21.

8. Eklund M, Sauer N, Schöne F, Messerschmidt U, Rosenfelder $P$, Htoo JK, et al. Effect of processing of rapeseed under defined conditions in a pilot plant on chemical composition and standardized ileal amino acid digestibility in rapeseed meal for pigs. J Anim Sci. 2015;93:2813-25.

9. ISO. Animal feeding stuffs. Determination of moisture and other volatile matter content. Geneva: International Standards Organisation; 1999.

10. AOAC. Protein (crude) in animal feed. Dumas method. AOAC International: Rockville, MD, USA; 1969

11. ISO. Animal feeding stuffs. Determination of nitrogen content and calculation of crude protein content. Part 1: Kjeldahl method. Geneva: International Standards Organisation; 2005.

12. ISO. Oilseed meals - Determination of oil content - Part 2: rapid extraction method. Geneva: International Standards Organization; 2008.
13. Van Soest PJ, Robertson JB, Lewis BA. Methods for dietary fiber, neutral detergent fiber, and nonstarch polysaccharides in relation to animal nutrition. J Dairy Sci. 1991;74:3583-97.

14. ISO. Animal feeding stuffs. Determination of amino acids content. Geneva: International Standards Organisation; 2005.

15. Moughan PJ, Rutherfurd SM. A new method for determining digestible reactive lysine in foods. J Agric Food Chem. 1996:44:2202-9.

16. ISO. Rapeseed. Determination of glucosinolates content. Part 1: method using high-performance liquid chromatography. Geneva: International Standards Organisation; 1992.

17. AOCS. Protein dispersibility index. Official Method Ba 10-65. Champaign: American Oil Chemists Society; 1980.

18. ISO. Oilseed meals. Determination of soluble proteins in potassium hydroxide solution. Geneva: International Standards Organisation; 2014.

19. Hu X, Kaplan D, Cebe P. Determining beta-sheet crystallinity in fibrous proteins by thermal analysis and infrared spectroscopy. Macromolecules. 2006:39:6161-70.

20. Carbonaro M, Maselli P, Dore P, Nucara A. Application of Fourier transform infrared spectroscopy to legume seed flour analysis. Food Chem. 2008; 108:361-8.

21. Boisen S, Fernández JA. Prediction of the apparent ileal digestibility of protein and amino acids in feedstuffs and feed mixtures for pigs by in vitro analyses. Anim Feed Sci Technol. 1995;51:29-43.

22. Pedersen B, Eggum BO. Prediction of protein digestibility by an in vitro enzymatic pH-stat procedure. Z Tierphysiol Tierernahr Futtermittelkd. 1983; 49:265-77.

23. Butré $\mathrm{Cl}$, Wierenga PA, Gruppen $\mathrm{H}$. Effects of ionic strength on the enzymatic hydrolysis of diluted and concentrated whey protein isolate. J Agric Food Chem. 2012;60:5644-51.

24. Wang W, Nema S, Teagarden D. Protein aggregation-Pathways and influencing factors. Int J Pharm. 2010;390:89-99.

25. Amin S, Barnett GV, Pathak JA, Roberts CJ, Sarangapani PS. Protein aggregation, particle formation, characterization \& rheology. Curr Opin Colloid Interface Sci. 2014;19:438-49.

26. Araba M, Dale NM. Evaluation of protein solubility as an indicator of overprocessing soybean meal. Poult Sci. 1990;69:76-83.

27. Parsons CM, Hashimoto K, Wedekind KJ, Baker DH. Soybean protein solubility in potassium hydroxide: an in vitro test of in vivo protein quality. J Anim Sci. 1991;69:2918-24

28. Anderson-Hafermann JC, Zhang Y, Parsons CM. Effects of processing on the nutritional quality of canola meal. Poult Sci. 1993;72:326-33.

29. Pastuszewska B, Jabłecki G, Buraczewska L, Dakowski P, Taciak M, Matyjek $R$,et al. The protein value of differently processed rapeseed solvent mea and cake assessed by in vitro methods and in tests with rats. Anim Feed Sci Technol. 2003:106:175-88.

30. Almeida FN, Htoo JK, Thomson J, Stein HH. Effects of heat treatment on the apparent and standardized ileal digestibility of amino acids in canola meal fed to growing pigs. Anim Feed Sci Technol. 2014;187:44-52.

31. Samadi, Theodoridou K, Yu P. Detect the sensitivity and response of protein molecular structure of whole canola seed (yellow and brown) to different heat processing methods and relation to protein utilization and availability using ATR-FT/IR molecular spectroscopy with chemometrics. Spectrochim Acta A Mol Biomol Spectrosc. 2013:105:304-13.

32. Secundo F, Guerrieri N. ATR-FT/R study on the interactions between gliadins and dextrin and their effects on protein secondary structure. J Agric Food Chem. 2005;53:1757-64.

33. van Rooijen C, Bosch G, van der Poel AFB, Wierenga PA, Alexander L, Hendriks $W H$. The Maillard reaction and pet food processing: effects on nutritive value and pet health. Nutr Res Rev. 2013;26:130-48.

34. Gonzalez-Vega JC, Kim BG, Htoo JK, Lemme A, Stein HH. Amino acid digestibility in heated soybean meal fed to growing pigs. J Anim Sci. 2011:89:3617-25.

35. Liu Y, Song M, Maison T, Stein HH. Effects of protein concentration and heat treatment on concentration of digestible and metabolizable energy and on amino acid digestibility in four sources of canola meal fed to growing pigs. J Anim Sci. 2014:92:4466-77.

36. Newkirk RW, Classen HL, Scott TA, Edney MJ. The digestibility and content of amino acids in toasted and non-toasted canola meals. Can J Anim Sci. 2003;83:131-9.

37. Oerlemans K, Barrett DM, Suades CB, Verkerk R, Dekker M. Thermal degradation of glucosinolates in red cabbage. Food Chem. 2006;95:19-29. 
38. Wolf JC, Thompson DR, Reineccius GA. Initial losses of available lysine in model systems. J Food Sci. 1977;42:1540-4.

39. Dudley-Cash WA. PDI may better indicate soybean meal quality than other indices. Feedstuffs. 2001;73:10-1.

40. Van Boxtel EL, Van Den Broek LAM, Koppelman SJ, Gruppen H. Legumin allergens from peanuts and soybeans: Effects of denaturation and aggregation on allergenicity. Mol Nutr Food Res. 2008;52:674-82.

41. Tripathi MK, Mishra AS. Glucosinolates in animal nutrition: A review. Anim Feed Sci Technol. 2007;132:1-27.

42. Woyengo TA, Beltranena E, Zijlstra RT. Effect of anti-nutritional factors of oilseed co-products on feed intake of pigs and poultry. Anim Feed Sci Technol. 2016. In press.

43. Zhou X, Young MG, Zamora V, Zijlstra RT, Beltranena E. Feeding increasing dietary inclusions of extruded Brassica juncea canola expeller-pressed cake on growth performance, carcass characteristics, and jowl fatty acids of growing-finishing pigs. Can J Anim Sci. 2014;94:331-42.

44. Landero JL, Beltranena E, Cervantes M, Araiza AB, Zijlstra RT. The effect of feeding expeller-pressed canola meal on growth performance and diet nutrient digestibility in weaned pigs. Anim Feed Sci Technol. 2012;171:240-5.

45. Landero JL, Beltranena E, Zijlstra RT. Growth performance and preference studies to evaluate solvent-extracted Brassica napus or Brassica juncea canola meal fed to weaned pigs. J Anim Sci. 2012;90:406-8.

Submit your next manuscript to BioMed Central and we will help you at every step:

- We accept pre-submission inquiries

- Our selector tool helps you to find the most relevant journal

- We provide round the clock customer support

- Convenient online submission

- Thorough peer review

- Inclusion in PubMed and all major indexing services

- Maximum visibility for your research

Submit your manuscript at www.biomedcentral.com/submit
Biomed Central 